\title{
Natural Dyes Extracted from Bioactive Components of Fruit Waste for Dye-Sensitized Solar Cell
}

\author{
I Nyoman Setiawan ${ }^{1 *}$, I.A Dwi Giriantari ${ }^{2}$, W.G Ariastina ${ }^{2}$, I.B Alit Swamardika ${ }^{2}$ \\ ${ }^{I}$ Doctoral Study Program of Engineering Science, University of Udayana, Denpasar, Bali, 80225, Indonesia. \\ ${ }^{2}$ Department of Electrical Engineering, University of Udayana, Badung, Bali 80362, Indonesia.
}

\begin{abstract}
DSSC using natural dyes extracted from bioactive components of red dragon fruit peel wastes were studied to determine the power conversion efficiency. Natural dyes were extracted by maceration method. Maceration is the soaking of fine powder from red dragon fruit peel for 24 hours in distilled water mixed with $10 \%$ citric acid with three variations of the material's weight ratio to the solvent, namely 1:4, 1:6 and 1:8. Materials were characterized by several tools such as SEM equipped with EDS, UV-Vis Spectrophotometry, and FTIR. The SEM analysis results with EDS showed that the $\mathrm{TiO}_{2}$ thin layer had mesoporous morphology and showed $\mathrm{Ti}$ and $\mathrm{O}$ without other impurities with a composition of $73.79 \%$ oxygen $(\mathrm{O})$ and $26.21 \%$ titanium (Ti). The results of UV-Vis characterization of the absorbance spectrum showed that there was absorption in the visible area, and the three samples of the dye solution had different absorbance power, photon energy, and absorption coefficient $(\alpha)$. FTIR analysis confirms that the sample shows a hydroxyl group, the building block for the anthocyanin structure. DSSC parameters were characterized using a solar simulator with $500 \mathrm{~W} / \mathrm{m}^{2}$ lighting. The best performance is obtained at a ratio of 1:8 with $\mathrm{Voc}=0.47 \mathrm{~V}, \mathrm{Jsc}=23.46 \mu \mathrm{Acm}^{-}$ ${ }^{2}$, Fill Factor $=0.480$ and efficiency $0.029 \%$
\end{abstract}

Keywords: Dye-sensitized solar cell, natural dye, $\mathrm{TiO}_{2}$, FTO

\section{INTRODUCTION}

Renewable energy becomes a crucial thing in preserving nature and the environment quality [1]. Besides, it has also been proven to improve economic growth because of its lower cost than non-renewable energy [2]. Sunlight is one of the renewable energy that doesn't cause environmental pollution and noise [3]. Among all renewable technologies, solar cell installation, or commonly known as photovoltaic (PV), has dominated the renewable energy industry. Solar cell technology continues to develop because this technology is considered an environmentally friendly alternative energy source expected to replace fossil energy sources. The advancement of solar cell technology aims to produce cheap and high-efficiency solar cells [4].

The first generation of solar cells used crystalline silicon material. This technology can produce high-efficiency solar cells, but the production costs are quite expensive. This wafer- based silicon solar cell panel still holds $90 \%$ of the worldwide PV production market [5].

Thin film technology is known as second-generation solar cells. Semiconductor materials are capable of producing thin-film cells, only a few micrometers thick [6]. The foremost materials in the manufacture of thin films are amorphous silicon (A-Si), cadmium telluride (CdTe), and copper indium gallium selenite (CIGS). This technology can be cheaper to produce but has a lower efficiency level than the first generation. In fact, this technology only contributes to 5\% of the global PV market [7].

The third generation, namely Dye-Sensitized Solar Cell (DSSC), invented by O'Regan and Gratzel in 1991, has become a significant concern on solar energy because of its simple fabrication, good efficiency and low production costs. DSSC is different from silicon solar cells. In the use of DSSC technology, light absorption and cargo carrier transport is separated. The dye molecule is responsible for absorbing light while the charge separation is carried out by nanocrystalline inorganic semiconductors, which have a wide band gap such as $\mathrm{TiO}_{2}$. In general, the DSSC has three main components. The three components are the working electrode, the counting electrode, and the electrolyte solution. The working electrode consists of transparent conductive glass such as Indium Tin Oxide (ITO) or Fluorine Tin. Oxide (FTO), nanocrystalline $\mathrm{TiO}_{2}$ semiconductor coating, and dye Counter electrode consists of transparent conductive glass that has been coated with carbon [8] or platinum [9]. The electrolyte used is an iodine trioxides electrolyte with a pair redox $\left(\mathrm{I}^{-} / \mathrm{I}_{3}^{-}\right)$.

Sensitizers have a significant role in absorbing photons that come from sunlight and convert them into electrical energy. In the DSSC studies that have been carried out, synthetic dyes can achieve a conversion efficiency of $11-12 \%$ [10]. Sensitizers from synthetic dyes have been shown to provide better results in increasing the efficiency and durability of DSSC. However, it does show some drawbacks: more expensive and potentially lethal materials [11]. Some researchers are trying to use natural dyes instead of synthetic dyes to produce a less expensive and environmentally friendly sensitizer. The research that has been done uses leaves, fruits, roots, and mushrooms as the basic ingredients for natural dyes [12] [13] [14] [15] [16]. In this research, a DSSC study was conducted using bioactive components of red dragon fruit peel waste. It has the potential to be a natural dye because it produces a red color produced by pigments called anthocyanins such as cyanidin-3-sophoroside 
and cyanidin-3-glucoside [17]. About 30-35\% of dragon fruit is the peel, usually disposed of as waste that can pollute the environment. Thus, the study's objective is to identify the possibility of bioactive components of red dragon fruit peel waste for DSSC and determine the effect of variations in the material's weight ratio with the solvent. Dye solvents use distilled water because they are non-toxic, easy to obtain, and cheap. The use of these natural dyes can reduce the costs and increase added value compared to using pulp. Besides, fruit peel utilization can reduce the production of more and more waste due to increased red dragon fruit consumption for health.

\section{MATERIALS AND METHODS}

\section{II.I Materials}

The materials used in this study were FTO TCO22-7 glass with a material resistance of $7 \mathrm{ohm} / \mathrm{sq}$ and $\mathrm{TiO}_{2}$ purchased from Solaronix SA. The $\mathrm{TiO}_{2}$ thin layer measuring 6 × $6 \mathrm{~mm}$ was made using the screen printing technique on FTO glass measuring $20 \times 20 \mathrm{~mm}$ and $2 \mathrm{~mm}$ thick. Red dragon fruit peel waste is used as a natural coloring agent.

\section{II.II Extraction of natural dyes}

The red dragon fruit peel is separated from the flesh and cut into small pieces. Then those samples were dried at room temperature in the laboratory. The dried sample was crushed in a blender to produce a fine powder. The dye solution was made by the maceration method. Maceration is soaking the fine powder of red dragon fruit peel for 24 hours in distilled water mixed with $10 \%$ citric acid, with three variations of the material's weight ratio to the solvent, namely 1:4 1:6 and 1: 8 . The extract is filtered with filter paper and accommodated in bottles.

\section{II.III DSSC assembly}

The making of working electrodes begins by immersing the conductive glass coated with $\mathrm{TiO}_{2}$ for 24 hours in the three variations of the solvent ratio. The Counter Electrode is made of platinum-coated FTO conductive glass. Making DSSC with a sandwich system, where the working electrodes are stacked with a counter electrode and electrolyte solution is dropped between the two electrodes (Iodolite HI-30). The two sides are clamped with a binder clip.

\section{II.IV Characterization}

The $\mathrm{TiO}_{2}$ thin layer on FTO glass was characterized by SEM equipped with EDS (JEOL-JSM-6510LA). The dye solution's characterization was carried out using Fourier Transform Infrared Spectrophotometer IRPrestige-21 and UV-Vis Spectrophotometry (UV-Vis-1800 Shimadzu). The dye band gap's determination absorbed by the $\mathrm{TiO}_{2}$ surface is calculated using the formula (1). Where $h$ is Planck's constant, $v$ is the frequency, $\lambda$ is the wavelength, and $\mathrm{c}$ is the light speed.

$$
\text { Photon Energy }(E)=h \cdot v=\frac{h \cdot c}{\lambda}
$$

The absorption coefficient determines the extent to which a material can penetrate a particular wavelength of light before being absorbed. The absorbance coefficient for each wavelength is obtained by dividing the absorbance by the wavelength shown in the formula (2) using Boltzmann's K constant [18].

$$
\text { absorption coefficient }(\alpha)=\frac{4 \pi k}{\lambda}
$$

The three DSSC samples that have been made were characterized by the Oriel Solar Simulator Model 81193 and the I-V meter Keithley 2400 Source Meter (SMU) instrument at the Electronics and Telecommunications Research Center, Indonesian Institute of Sciences (P2ET-LIPI) Bandung. The short circuit current Isc or Jsc and the open-circuit voltage Voc are determined from the I-V curve. Jsc is the current density, i.e., Isc divided by the area of the active cell. The maximum output power (Pmax) is determined when the product and voltage are maximum. Pmax can be calculated by equation (3).

$$
P_{\text {max }}=V_{m p} \cdot I_{m p}=V_{m p} \cdot J_{m p}
$$

Imp and Vmp are the values of current and voltage at maximum power, respectively. The fill factor (FF) measures the device's ideality and is defined as the maximum power output ratio per unit area to the Voc and Isc products. The fill factor (FF) is calculated by equation (4).

$$
F F=\frac{V_{m p} \cdot I_{m p}}{V_{o c} \cdot I_{s c}}=\frac{V_{m p} \cdot J_{m p}}{V_{o c} \cdot J_{s c}}
$$

The overall efficiency of converting solar energy to solar cell electricity is defined as the maximum cell output ratio divided by incident light power. This can be determined by the measured photo current density at short circuit (Isc), opencircuit voltage (Voc), Fill Factor (FF), and incident light intensity (Pin), incident irradiation power (Ein), active cell surface area. (A) [19], as shown in equation (5) below.

$$
\eta=\frac{P_{\max }}{P_{\text {in }}}=\frac{V_{m p} \cdot I_{m p}}{E_{i n} \cdot A}=\frac{V_{o c} \cdot I_{s c} \cdot F F}{E_{i n} \cdot A}=\frac{V_{o c} \cdot J_{s c} \cdot F F}{E_{i n} \cdot A}
$$

\section{RESULTS AND DISCUSSION}

Scanning Electron Microscope (SEM) is an electron microscope used to directly investigate solid objects' surface. The characterization of $\mathrm{TiO}_{2}$ thin films to see the morphology was carried out by SEM JEOL JSM-6510 LA at an acceleration voltage of $15 \mathrm{kV}$ and magnification of 25,000 times, and the results are as shown in Fig. 1.

In general, the particles produced are mesoporous and are on the micrometer size scale. In addition to the $\mathrm{TiO}_{2}$ thin film's morphology, it was also characterized by Energy Dispersive Spectroscopy (EDS). EDS is an analytical technique for analyzing the elements or characteristics of a chemical object. EDS is used to verify titanium and oxygen content and the absence of other contaminants to maintain sample quality. The $\mathrm{TiO}_{2}$ thin layer's analysis results on FTO TCO22-7 glass with 
EDS (JEOL-JSM-6510LA) at an acceleration voltage of $20 \mathrm{kV}$, a probe current of $7.47500 \mathrm{nA}$ and a magnification of 3,000 times is shown in Fig. 2.

The investigation results show the presence of $\mathrm{Ti}$ and $\mathrm{O}$ without other impurities with a composition of $73.79 \%$ oxygen $(\mathrm{O})$ and $26.21 \%$ titanium $(\mathrm{Ti})$.

Optical characterization of the three red dragon fruit peel dye solution samples using a UV-Vis (UV-1800 Shimadzu) spectrophotometer in the wavelength range of $400-800 \mathrm{~nm}$, visible light spectrum. Within this wavelength range, organic dyes are naturally effective in absorbing light in visible light during the photosynthesis process. The results of the absorbance spectrum characterization are shown in Fig.3.

The three sample solutions have different absorption peaks. The absorption peak at this wavelength indicates the presence of anthocyanin content in the dye. The highest absorption peak was obtained at a ratio of $1: 4$, namely 0.587 , at a wavelength of $533.50 \mathrm{~nm}$. All the pigments can absorb photons of light and generate excited electrons. The process allows a $\mathrm{TiO}_{2}$ conduction band with acceptable performance to increase the DSSC conversion efficiency [20]. Dyes containing anthocyanin pigments have sufficient hydroxyl groups to attach $\mathrm{TiO}_{2}$ firmly and can inject electrons into the $\mathrm{TiO}_{2}$ conduction band when excited by visible light [21]. Low efficiency is the major problem in DSSC. The cause is the weak bond between the dye molecule and $\mathrm{TiO}_{2}$, whose electrons can be carried from the excited state molecule in the $\mathrm{TiO}_{2}$ film [22]. So that the use of dyes from dragon fruit peel can increase the interface between the sensitizers and the molecules of $\mathrm{TiO}_{2}$, which are interconnected to improve the efficiency of DSSC conversion. The energy discrepancy between the conduction band and the valence band is known as the band gap energy, which in DSSC performance is related to the absorbed solar energy. The results of the three samples' characterization of the absorbance spectrum have differences in photon energy and absorption coefficient $(\alpha)$, as in Table 1.

The dye solution was characterized by Fourier Transform Infrared (FTIR) Spectroscopy Prestige 21 produced by Shimadzu Japan from a wavenumber $400-4000 \mathrm{~cm}^{-1}$, and the results are as shown in Fig. 4.

The absorption peak in the infrared spectrum indicates that the absorption is related to the functional groups contained in the dye. The $\mathrm{OH}$ functional groups are identified in wave numbers $3651.25 \mathrm{~cm}^{-1}$, up to $2872.01 \mathrm{~cm}^{-1}$, as shown in Table 2 [23].

The O-H functional group is a hydroxyl group that makes up the anthocyanin structure. The hydroxyl group functions as an adhesive for the pigment compound and $\mathrm{TiO}_{2}$ layer on the FTO. Red dragon fruit peel dye molecules containing hydroxyl and carbonyl groups prove the interaction between $\mathrm{TiO}_{2}$ and dye as functional groups that can interact on the $\mathrm{TiO}_{2}$ surface [24], which will contribute to the efficiency of photovoltaic conversion [25].

In this research, red dragon fruit peel waste was successfully used to make natural dyes in the DSSC prototype. Table 3 summarizes the short-circuit current, open-circuit voltage, fill factor, and efficiency extracted from the I-V curve.
The voltage and current output results obtained using the Solar Simulator AM 1.5 light source and equipped with a pyranometer sensor with an Intensity of $500 \mathrm{~W} / \mathrm{m}^{2}$ show that the resulting voltage is appropriate and constant. Still, the resulting current is not ideal [26]. The voltage on the DSSCbased solar cell is generated from the distinction of the conduction energy level of the $\mathrm{TiO}_{2}$ semiconductor electrode with the electrochemical potential of the resulting current redox electrolyte pair concerning the number of photons involved in the conversion process. Overall, the flow obtained is still small. The small output current generated is due to the very large resistance of the $\mathrm{TiO}_{2}$ semiconductor electrode layer and electrolyte due to the fast drying electrolyte. The main factor affecting resistance is electrolytes [27]. With this very large resistance value, the dye's injected electrons experience a very large resistance in the $\mathrm{TiO}_{2}$ layer. It makes the number of electrons flowing into the circuit the outermost becomes small.

Another cause can be caused by the dye's inadequate function in forming and injecting electrons into the $\mathrm{TiO}_{2}$ electrode layer. DSSC efficiency is influenced by three parameters, namely, Isc (short circuit current), Voc (open circuit voltage), and FF (Fill Factor). Isc is a short circuit that occurs when the voltage can equal zero. This current is equal to the number of photons converted into electron-hole pairs. The more electrons are excited, the greater the resulting efficiency. Voc is the voltage value when the current is zero because all the excitons are combined so that no current flows in the DSSC. FF is the ratio of maximum power (Pmax) to short circuit current (Isc) and open-circuit voltage (Voc). Several factors can influence FF. One of them is high internal resistance that causes low fill factors and decreased efficiency. The increase in electron mobility affects the increase in the charging factor. Increasing electron mobility increases current. The best performance is obtained at a ratio of $1: 8$ with $\mathrm{Voc}=0.47 \mathrm{~V}, \mathrm{Jsc}=23.46 \mu \mathrm{Acm}^{-}$ 2 , Fill Factor $=0.480$ and efficiency $0.029 \%$. These results prove that natural dyes made from the use of red dragon fruit peel waste can be used as a sensitizer. However, further research to improve the DSSC efficiency through optimization of current and voltage is necessary.

\section{CONCLUSION}

An investigation was carried out to determine DSSC power conversion efficiency using natural dyes extracted from bioactive components of red dragon fruit peel waste. SEM analysis results equipped with EDS showed that the $\mathrm{TiO}_{2}$ thin layer had mesoporous morphology and $\mathrm{Ti}$ and O's presence without other impurities. The composition of $73.79 \%$ oxygen (O) and $26.21 \%$ titanium (Ti). The results of UV-Vis characterization of the absorbance spectrum showed that there was absorption in the visible area, and the three samples of the dye solution had different absorbance power, photon energy, and absorption coefficient $(\alpha)$. FTIR analysis confirms that the sample shows a hydroxyl group, the building block for the anthocyanin structure. This hydroxyl group is suitable as an adhesive between pigment compounds and a thin layer of $\mathrm{TiO}_{2}$ on FTO. The created DSSC parameters are determined under $500 \mathrm{~W} / \mathrm{m}^{2}$ lighting. It is known that the voltage generated is good, but the current obtained is still small. The small output 
International Journal of Engineering Research and Technology. ISSN 0974-3154, Volume 13, Number 9 (2020), pp. 2498-2504

(C) International Research Publication House. https://dx.doi.org/10.37624/IJERT/13.9.2020.2498-2504

current generated is due to the very large resistance of the $\mathrm{TiO}_{2}$ semiconductor electrode layer and electrolyte due to the fast drying electrolyte. The best performance is obtained at a ratio of $1: 8$, with an efficiency of $0.029 \%$. Although the efficiencies obtained are still low, the results are encouraging and could lead to additional research-oriented towards finding new, naturally sensitive substances.

Table 1. Photon energy and absorption coefficient $(\alpha)$ of natural dye from red dragon fruit peel waste

\begin{tabular}{|c|c|c|c|c|}
\hline Ratio & Wavelength (nm) & Peak Absorbance & $\begin{array}{c}\text { Photon Energy } \\
(\mathbf{e V})\end{array}$ & $\begin{array}{c}\text { Absorption coefficient } \\
(\boldsymbol{\alpha})\left(\mathbf{k m}^{-1}\right)\end{array}$ \\
\hline $1: 4$ & 533.50 & 0,587 & 2.33 & 2.029 \\
\hline $1: 6$ & 541.00 & 0,313 & 2.30 & 2.001 \\
\hline $1: 8$ & 535.50 & 0,233 & 2.32 & 2.021 \\
\hline
\end{tabular}

Table 2. FTIR spectrum peaks in red dragon fruit peel dye solution

\begin{tabular}{|c|c|c|c|c|c|}
\hline \multicolumn{2}{|c|}{ Ratio 1:4 } & \multicolumn{2}{c|}{ Ratio $1: 6$} & \multicolumn{2}{c|}{ Ratio 1:8 } \\
\hline Peak $\left(\mathrm{cm}^{-1}\right)$ & Intensity $(\%)$ & Peak $\left(\mathrm{cm}^{-1}\right)$ & Intensity $(\%)$ & Peak $\left(\mathrm{cm}^{-1}\right)$ & Intensity $(\%)$ \\
\hline 416.620 & 50.176 & 449.410 & 56.717 & 455.200 & 62.581 \\
\hline 526.570 & 54.208 & 528.500 & 57.846 & 522.710 & 61.953 \\
\hline 858.320 & 22.443 & 891.110 & 21.874 & 860.250 & 23.695 \\
\hline 1130.290 & 30.608 & 1132.210 & 30.135 & 1128.360 & 31.930 \\
\hline 1394.530 & 32.021 & 1394.530 & 31.447 & 1249.870 & 30.723 \\
\hline 1508.330 & 31.759 & 1412.190 & 31.107 & 1394.530 & 32.976 \\
\hline 1695.430 & 27.056 & 1695.430 & 26.212 & 1514.120 & 32.520 \\
\hline 2376.300 & 35.052 & 1774.510 & 26.523 & 1697.360 & 27.223 \\
\hline 2872.010 & 47.418 & 2378.230 & 34.465 & 2382.090 & 35.673 \\
\hline 2997.380 & 47.358 & 2872.010 & 48.032 & 2875.860 & 48.574 \\
\hline 3278.990 & 56.402 & 3261.630 & 57.654 & 2989.660 & 48.940 \\
\hline 3651.250 & 17.737 & 3651.250 & 16.127 & 3622.320 & 17.409 \\
\hline
\end{tabular}

Table 3. DSSC performance is based on natural dyes extracted from red dragon fruit peel waste with various solvent ratios

\begin{tabular}{|c|c|c|c|c|c|c|c|c|}
\hline Ratio & $\begin{array}{c}\mathrm{V}_{\mathrm{OC}} \\
(\mathrm{V})\end{array}$ & $\begin{array}{c}\mathrm{J}_{\mathrm{SC}} \\
\left(\mu \mathrm{Acm}^{-2}\right)\end{array}$ & $\begin{array}{c}\mathrm{V}_{\mathrm{mp}} \\
(\mathrm{V})\end{array}$ & $\begin{array}{c}\mathrm{J}_{\mathrm{mp}} \\
\left(\mu \mathrm{Acm}^{-2}\right)\end{array}$ & $\begin{array}{c}\mathrm{P}_{\mathrm{in}} \\
\left(\mathrm{Wcm}^{-2}\right)\end{array}$ & $\begin{array}{c}\mathrm{P}_{\max } \\
\left(\mu \mathrm{Wcm}^{-2}\right)\end{array}$ & $\begin{array}{c}\text { Fill } \\
\text { Factor }\end{array}$ & $\begin{array}{c}\text { Efficiency } \\
(\%)\end{array}$ \\
\hline $1: 4$ & 0.26 & 19.74 & 0.15 & 10.23 & 0.018 & 1.534 & 0.299 & 0.009 \\
\hline $1: 6$ & 0.40 & 23.60 & 0.28 & 14.96 & 0.018 & 4.189 & 0.444 & 0.023 \\
\hline $1: 8$ & 0.47 & 23.46 & 0.33 & 16.05 & 0.018 & 5.295 & 0.480 & 0.029 \\
\hline
\end{tabular}


International Journal of Engineering Research and Technology. ISSN 0974-3154, Volume 13, Number 9 (2020), pp. 2498-2504

(C) International Research Publication House. https://dx.doi.org/10.37624/IJERT/13.9.2020.2498-2504

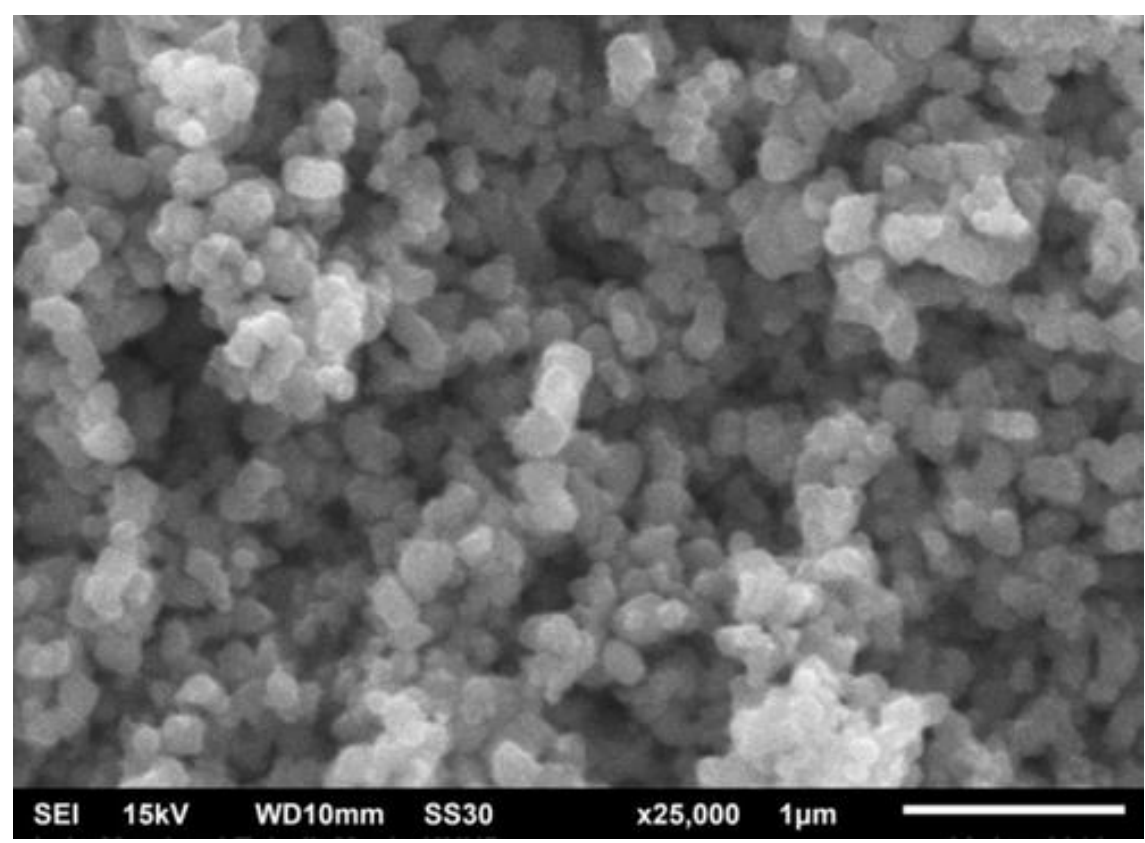

Fig. 1. Characterization of the $\mathrm{TiO}_{2}$ thin film morphology by SEM

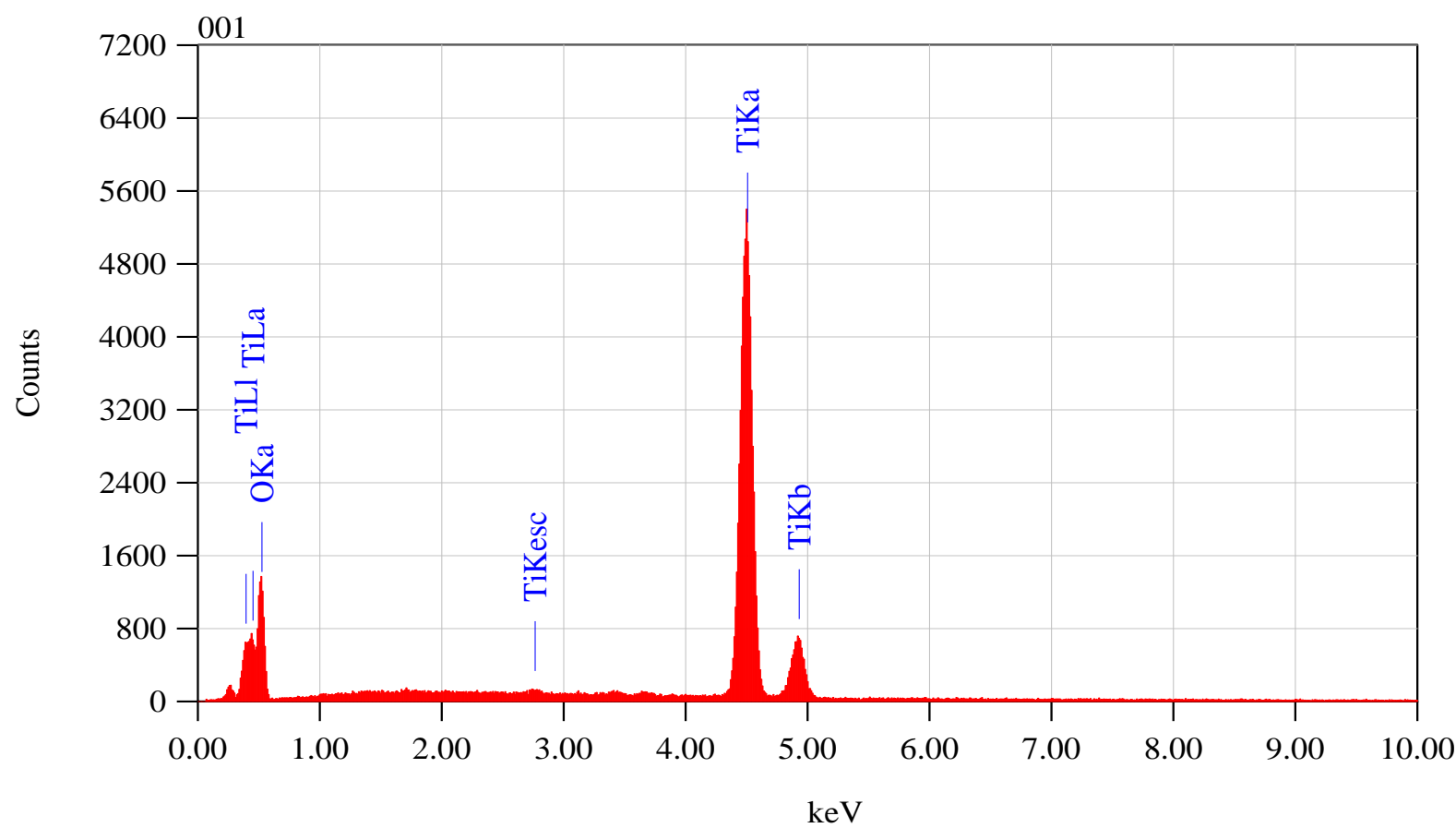

ZAF Method Standard less Quantitative Analysis

Fitting Coefficient : 0.2158

Element (keV) Mass\% Sigma Atom\% Compound Mass\% Cation K

\begin{tabular}{|c|c|c|c|c|c|}
\hline $\mathrm{O} K$ & 0.525 & 48.46 & 0.58 & 73.79 & 24.9038 \\
\hline K & 4.508 & 51.54 & 0.27 & 26.21 & 75.0963 \\
\hline
\end{tabular}

Total

100.00

100.00

Fig. 2. Graph of $\mathrm{TiO}_{2}$ thin film element analysis 
International Journal of Engineering Research and Technology. ISSN 0974-3154, Volume 13, Number 9 (2020), pp. 2498-2504

(C) International Research Publication House. https://dx.doi.org/10.37624/IJERT/13.9.2020.2498-2504

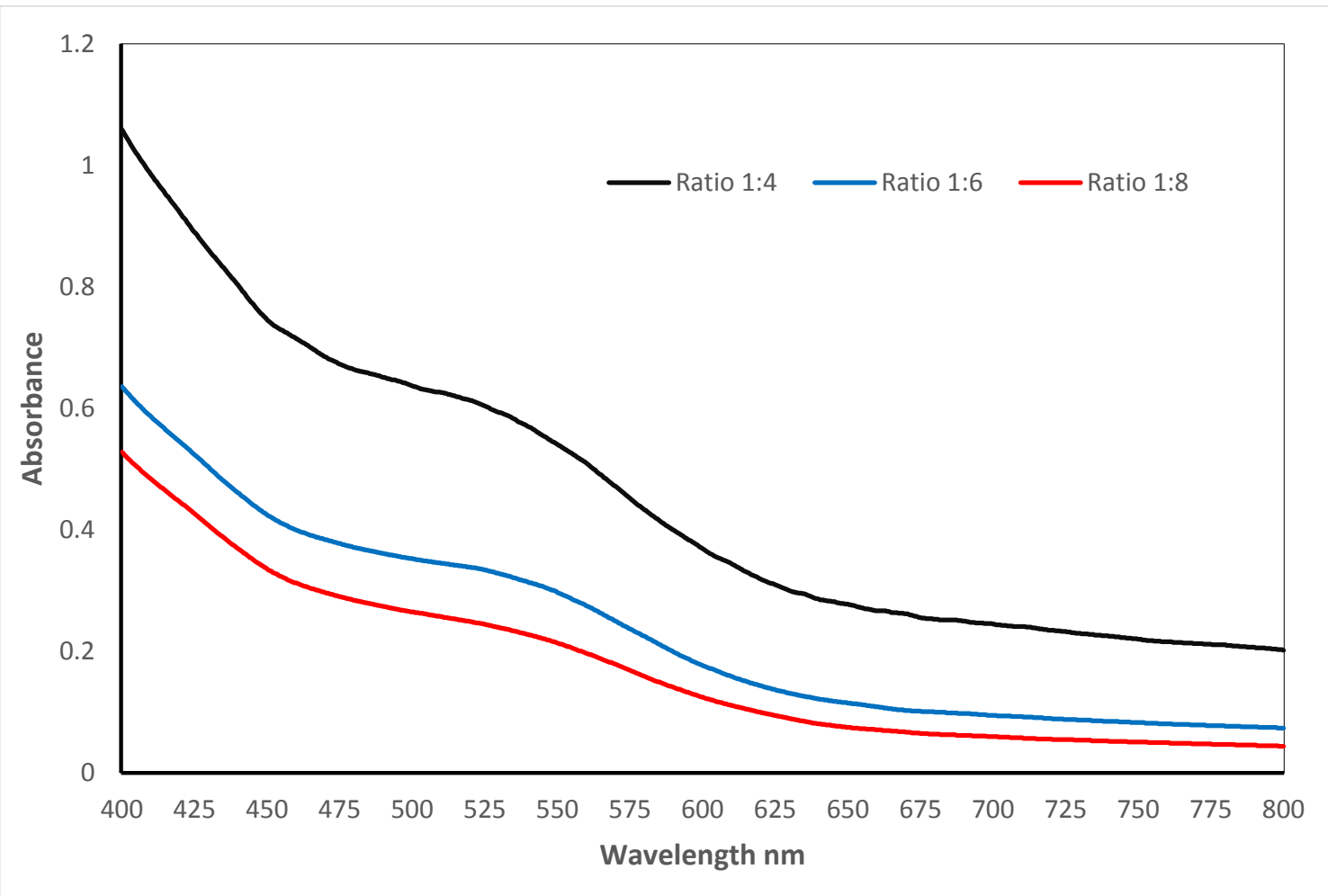

Fig. 3. UV-Vis spectrum of red dragon fruit peel dye

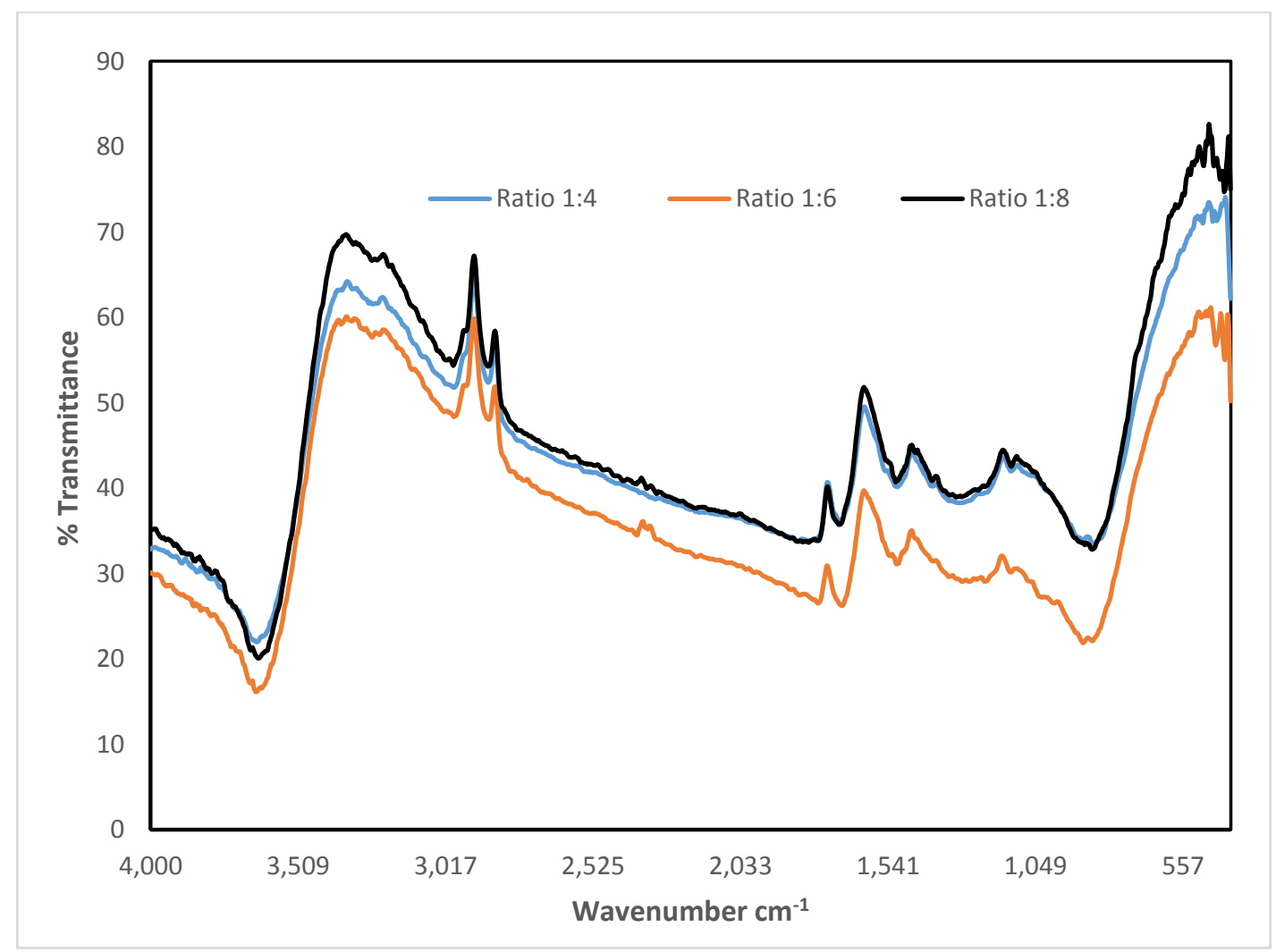

Fig. 4. The results of FTIR analysis of red dragon fruit peel with various solvent ratios 
International Journal of Engineering Research and Technology. ISSN 0974-3154, Volume 13, Number 9 (2020), pp. 2498-2504

(C) International Research Publication House. https://dx.doi.org/10.37624/IJERT/13.9.2020.2498-2504

\section{REFERENCES}

[1] R. Khan, Z. Yu, A. Belhadi, A. Mardani and S. Abdul, "Investigating the effects of renewable energy on international trade and environmental quality," Journal of Environmental Management, vol. 272, p. 111089, 2020.

[2] M. Shahbaz, C. Raghutla, K. R. Chittedi, Z. Jiao and X. V. Vo, "The effect of renewable energy consumption on economic growth: Evidence from the renewable energy country attractive index," Energy, vol. 207, p. 118162, 2020.

[3] S. Sharma, K. K. Jain and A. Sharma, "Solar Cells: In Research and Applications-A Review," Materials Sciences and Applications, vol. 6, pp. 1145-1155, 2015.

[4] M. A. Green, "Photovoltaic technology and visions for the future," Progress in Energy, vol. 1, no. 1, 2019.

[5] L. C. Andreani, A. Bozzola, P. Kowalczewski, M. Liscidini and L. Redorici, "Silicon solar cells: Toward the efficiency limits," Advances in Physics: X, vol. 4, no. 1, pp. 125-47, 2019.

[6] S. Battersby, "The solar cell of the future," Proceeding of the National Academy of Sciences of the United States of America, vol. 116, no. 1, pp. 7-10, 2019.

[7] Global Data, "Solar PV module, Update 2018: Global market size, competitive landscape and key country analysis to 2022," Global Data, London, 2018.

[8] S. Widodoa, G. Wirantoa and M. N. Hidayat, "Fabrication of dye sensitized solarcells with spray coated carbonnano tube (CNT) based counter electrodes," Energy Procedia, vol. 68, pp. 37-44, 2015.

[9] T. Adachi and H. Hoshi, "Preparation and characterization of Pt/carbon counter electrodes for dye-sensitized solar cells," Materials Letters, vol. 91, pp. 15-18, 2013.

[10] R. Buscaino, C. Baiocchi and B. C., "Inorganica Chimica," Acta, vol. 361, no. 3, p. 798-805, 2008.

[11] N. Prabavathy, S. Shalini, R. Balasundaraprabhu, D. Velauthapillai, S. Prasanna and N. Muthukumarasamy, "Enhancement in the photostability of natural dyes for dyesensitized solar cell (DSSC) applications: a review," International Journal of Energy Research, vol. 41, no. 10, pp. 1372-1396, 2017.

[12] N. Ananthi, M. S. P. Subathra, S. C. Emmanuel and N. M. Kumar, "Preparation and characterization of two dyesensitized solar cells using Acalypha Godseffia and Epipremnum Aureum dyes as sensitizers," Energy Sources, Part A: Recovery, Utilization, and Environmental Effects, vol. 42, no. 13, pp. 1662-1673, 2019.

[13] D. Tahir, W. Satriani, P. L. Gareso and B. Abdullah, "Dye sensitized solar cell (DSSC) with natural dyes extracted from Jatrophaleaves and purple Chrysanthemumflowers as sensitizer," Journal of Physics: Conference Series, vol. 979, pp. 1-7, 2018.

[14] A. M. Ammar, H. S. H. Mohamed, M. M. K. Yousef, G. M. Abdel-Hafez, A. S. Hassanien and A. S. G. Khalil, "DyeSensitized Solar Cells (DSSCs) Based on ExtractedNatural Dyes," Journal of Nanomaterials, vol. 2019, pp. 1-10, 2019.

[15] M. Zalas, B. Gierczyk, H. Bogacki and G. Schroeder, "The Cortinarius Fungi Dyes as Sensitizers in Dye-Sensitized
Solar Cells, Hindawi Publishing Corporation," International Journalof Photoenergy, vol. 2015, pp. Article ID 653740, 6 pages, 2015.

[16] K. Maabong, C. M. Muiva, P. Monowe, T. S. Sathiaraj, M. Hopkins, L. Nguyen, K. Malungwa and M. Thobega, "Natural Pigments as Photosensitizers for Dye-Sensitized Solar Cells with TiO2 Thin Films," International Journal of Renewable Energy Research, vol. 5, no. 1, pp. 54-60, 2015.

[17] R. Worlstad, Anthocyanins Natural Food Colorants, Science and Technology, New York: Marcel Dekker, 2000.

[18] L. Pitre, M. D. Plimmer, F. Sparasci and M. E. Himbert, "Determinations of the Boltzmann constant Déterminations de la constante de Boltzmann," Comptes Rendus Physique, vol. 20, no. 1-2, pp. 129-139, 2019.

[19] Y. Gentian, X. Ma, W. Zhang, F. Li, J. Wu and G. Li, "A highly efficient flexible dye-sensitized solar cell based on nickel sulfide/platinum/titanium counter electrode," Nanoscale Research Letters, vol. 10, no. 1, pp. 1-9, 2015.

[20] M. A. Al-Alwani, A. B. Mohamad, A. Kadhum and N. A. Ludin, " Effect of solvents on extracting natural pigments and adsorption onto $\mathrm{TiO} 2$ for dye-sensitized solar cell applications," Spectrochimica Acta Part A: Molecular and Biomolecular Spectroscopy, vol. 138, pp. 130-137, 2015.

[21] E. S. VH and S. A. Wicaksana, "Potential of Purple Cabbage (Brassica oleracea var. capitata f.) and Duwet Fruit (Eugenia cumini) as sensitizers in Dye Sensitized Solar Cell (DSSC)," IOP Conference Series: Materials Science and Engineering, vol. 546, pp. 1-6, 2019.

[22] I. A. D. A. Alhamed M, "Studying of Natural Dyes Properties as Photo-Sensitizer for Dye Sensitized Solar Cells(DSSC)," Journal of Electron Devices, vol. 16, pp. 1370-1383, 2012.

[23] N. E. Safie, N. A. Ludin, M. S. Su'ait, N. H. Hamid, S. Sepeai, M. A. Ibrahim and M. A. M. Teridi, "Preliminary study of natural pigments photochemical properties of Curcumalonga L. and Lawsonia inermis L. as $\mathrm{TiO} 2$ photoelectrode sensitizer," Malaysia Journal of Analytical Sciences, vol. 19, no. 6, pp. 1243-1249 [, 2015.

[24] K. V. Hemalatha, S. N. Karthick, C. Justin Raj, N. Y. Hong, S. K. Kim and H. J. Kim, "Performance of Kerria japonica and Rosa chinensis flower dyes as sensitizers for dyesensitized solar cells," Spectrochimica Acta - Part A: Molecular and Biomolecular Spectroscopy, vol. 96, pp. 305309, 2012

[25] M. R. Narayan, "Review: Dye sensitized solar cells based on natural photosensitizers," Renewable and Sustainable Energy Reviews , vol. 16, no. 2012, pp. 208-215 , 2012.

[26] K. Mertens, Photovoltaics: fundamentals, technology and practice, West Sussex: John Wiley \& Sons Ltd, 2014.

[27] R.-Y. Yang, H.-Y. Chen and F.-D. Lai, "Performance Degradation of Dye-Sensitized Solar CellsInduced by Electrolytes," Advances in Materials Science and Engineering, vol. 2012, pp. Article ID 902146, 4 pages, 2012. 